\title{
Autour d'un cabinet de lecture, textes réunis par Graham Falconer
}

\section{Catherine Gaviglio-Faivre D'arcier}

\section{(2) OpenEdition}

10 Journals

\section{Édition électronique}

URL : https://journals.openedition.org/studifrancesi/40831

DOI : 10.4000/studifrancesi.40831

ISSN : 2421-5856

Éditeur

Rosenberg \& Sellier

\section{Édition imprimée}

Date de publication : 1 juillet 2004

Pagination : 202-203

ISSN : 0039-2944

\section{Référence électronique}

Catherine Gaviglio-Faivre D'arcier, "Autour d"un cabinet de lecture, textes réunis par Graham Falconer », Studi Francesi [En ligne], 142 (XLVIII | I) | 2004, mis en ligne le 30 novembre 2015, consulté le 09 septembre 2021. URL : http://journals.openedition.org/studifrancesi/40831 ; DOI : https://doi.org/ 10.4000/studifrancesi.40831

Ce document a été généré automatiquement le 9 septembre 2021.

\section{(c)}

Studi Francesi è distribuita con Licenza Creative Commons Attribuzione - Non commerciale - Non opere derivate 4.0 Internazionale. 


\title{
Autour d'un cabinet de lecture, textes réunis par Graham Falconer
}

\author{
Catherine Gaviglio-Faivre D'arcier
}

\section{RÉFÉRENCE}

AA. VV., Autour d'un cabinet de lecture, textes réunis par Graham FALCONER, Toronto, Centre d'études du XIX siècle Joseph Sablé, «A la recherche du XIXe siècle», 2001, pp. 271.

1 Le don par J. Sablé, au centre qui porte désormais son nom, du fonds d'un cabinet de lecture bordelais, est l'occasion d'une réunion d'études autour d'une institution qui, pendant plus de deux siècles, contribua à l'alphabétisation des Français. Les travaux pionniers de Françoise Parent-Lardeur au début des années 1980 avaient permis de déblayer le terrain grâce à l'exploitation du fonds $Q 28$ de la Bibliothèque nationale de France (alors partiellement accessible seulement). Le présent recueil, qui permet de nuancer certaines idées reçues, illustre aussi la diversité des approches possibles d'un même phénomène.

2 Celui-ci, comme l'explique Jean-Yves MOLLIER, même s'il a connu un recul à Paris à partir des années 1840, n'en est pas moins resté pérenne pendant plus de deux siècles, en province en particulier, en raison des carences du réseau des bibliothèques publiques (p.41-53). Mais, pris entre librairie et bibliothèque, le cabinet de lecture n'a pas manqué aussi de susciter de longs débats au cours de son existence. En 1837 déjà, L.Cassandra Hamrick le rappelle, la presse s'est fait l'écho d'une crise littéraire liée à l'apparition d'une presse à bon marché, à la transformation de l'homme de lettres en marchand de prose, à l'augmentation du nombre de lecteurs et à la cherté des livres, éléments qui favorisaient la prospérité des cabinets de lecture (p. 68-90). En 1920 encore, comme le montre l'enquête menée par L'Intransigeant auprès des auteurs (Proust par exemple) et publiée par Stéphane Vachon, le cabinet de lecture ne laissait personne indifférent (p. 153-180). 
3 Au-delà des débats, une analyse littéraire du phénomène, conduite par Alain vaILLANT, révèle des liens entre l'histoire des cabinets de lecture et l'émergence du roman comme genre à part entière. Le relatif déclin des cabinets dans la capitale a incité le roman, dénué de tradition, à se déporter vers la demande du public et à adopter un autre mode de publication (le roman-feuilleton): la force du livre multiplié s'est alors substituée à la parole singulière $\mathrm{du}$ poète. Un tel fait pourrait d'ailleurs être rapproché de la transformation du statut de l'auteur, à étudier à travers la présentation des livres, longtemps par titre plutôt que par auteur, dans les catalogues (p. 91-102).

4 Quel public fréquentait ces cabinets de lecture? Qu'y venait-il chercher? Ces deux questions, difficiles à appréhender, trouvent des éléments de réponse et de nuance grâce à la publication d'une (trop rare) liste de clients, du rapport de fonctionnement d'une salle de lecture anglaise à Bordeaux (p. 124-151), d'extraits de catalogues enfin (p. 185-271). La clientèle, contrairement aux idées reçues, apparaît très variée, avec parfois une forte proportion de petites gens (de nombreux marins anglais par exemple). Elle y venait attirée par une offre qui ne comptait pas seulement des romans (certains catalogues proposent aussi des ouvrages de pédagogie), même si ceux-ci constituaient la majorité des fonds.

Or, les romans visaient souvent un public féminin, dont Danielle CONSTANTIN mesure l'inscription dans deux ouvrages de Camille Bodin et de George Sand, écrits par et sur des femmes, mais dans des optiques différentes: le premier reste dans les limites de l'idéologie de l'époque, le second la conteste (p. 103-124). Une femme, en tout cas, trouvait peut-être dans un cabinet de lecture ce qu'une érudite provinciale comme Leroyer de Chantepie, présentée par James SMITH ALLEN, vivait grâce à sa communauté littéraire: des facilités de lecture et la possibilité d'exercer sa réflexion critique (p. 55-67).

6 Très présentes dans les livres comme auteur, héros et lecteur, les femmes l'étaient aussi au sein même des cabinets de lecture, dans le domaine commercial. La généalogie que dresse G. Falconer du cabinet Magen (1817-1862), repris par Emma DESBoIs sur plus d'un tiers de siècle (1872-?), en est l'illustration (p. 27-40). De plus, cette étude offre un condensé des conclusions de l'ouvrage: les cabinets de lecture connurent un déclin relatif plutôt qu'une disparition progressive à partir des années 1840 ; ils jouèrent un rôle de conservation (relayé plus tard par les bibliothèques publiques); ils offrirent aux femmes un espace de reconnaissance; enfin, leurs propriétaires cumulaient souvent diverses activités professionnelles.

7 Au carrefour des histoires de la librairie, de la littérature, de la lecture et de la condition féminine, l'étude des cabinets de lecture offre un vaste champ d'investigation aux chercheurs. 